
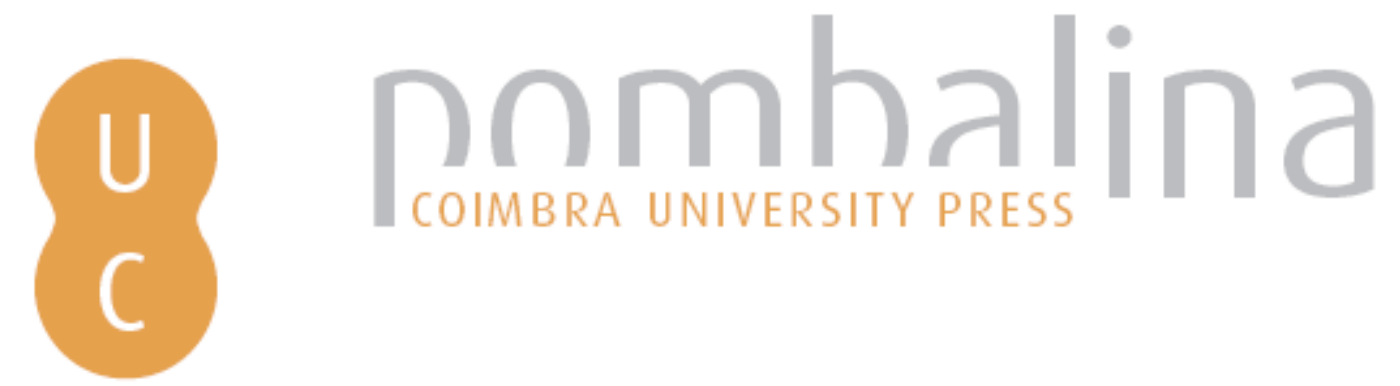

\title{
Platão e os Guaranis: utopias transatlânticas na obra De Administratione guaranica comparata ad Rempublicam Platonis commentarius de José Manuel Peramás
}
Autor(es):
Cornelli, Gabriele
Publicado por: Imprensa da Universidade de Coimbra; Annablume
URL
persistente:
URI:http://hdl.handle.net/10316.2/40843
DOI:
DOI:https://doi.org/10.14195/978-989-26-1288-1_2
Accessed : $\quad$ 26-Apr-2023 15:54:57

A navegação consulta e descarregamento dos títulos inseridos nas Bibliotecas Digitais UC Digitalis, UC Pombalina e UC Impactum, pressupõem a aceitação plena e sem reservas dos Termos e Condições de Uso destas Bibliotecas Digitais, disponíveis em https://digitalis.uc.pt/pt-pt/termos.

Conforme exposto nos referidos Termos e Condições de Uso, o descarregamento de títulos de acesso restrito requer uma licença válida de autorização devendo o utilizador aceder ao(s) documento(s) a partir de um endereço de IP da instituição detentora da supramencionada licença.

Ao utilizador é apenas permitido o descarregamento para uso pessoal, pelo que o emprego do(s) título(s) descarregado(s) para outro fim, designadamente comercial, carece de autorização do respetivo autor ou editor da obra.

Na medida em que todas as obras da UC Digitalis se encontram protegidas pelo Código do Direito de Autor e Direitos Conexos e demais legislação aplicável, toda a cópia, parcial ou total, deste documento, nos casos em que é legalmente admitida, deverá conter ou fazer-se acompanhar por este aviso.

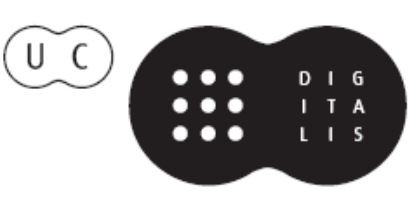




\section{Cosmópolis}

\section{mobilidades culturais às origens do pensamento antigo}

Gabriele Cornelli, Maria do Céu Fialho e Delfim Leão

\section{(coords.)}

IMPRENSA DA UNIVERSIDADE DE COIMBRA 


\title{
Platão e os Guaranis: Utopias transatlânticas na obra DE ADMINISTR ATIONE GUARANICA COMPARATA AD REMPUBLICAM Platonis commentarius de José Manuel Peramás
} (Plato and the Guaraní: transatlantic utopias in the work De Administratione guaranica comparata ad Rempublicam Platonis commentarius by José Manuel Peramás)

\author{
Gabriele Cornelli (cornelli@unb.br) \\ Cátedra UNESCO Archai, Universidade de Brasília
}

\begin{abstract}
Resumo: O presente ensaio dedica-se ao estudo da obra De Administratione guaranica comparata ad Rempublicam Platonis commentarius, escrita pelo jesuíta catalão José Manuel Peramás e publicada em 1793. A obra é concebida em polêmica com as utopias liberais e ilustradas modernas que o autor qualifica como epicuristas e desrespeitosas das santas instituições. Neste intento polêmico Peramás recupera a utopia política de Platão, expressa tanto na República como especialmente nas Leis. O argumento mais contundente na polêmica de Peramás com as utopias liberais de seu tempo é que entre os Guaranis das Missões, em terras americanas - ao dizer do autor - se realizou, ao menos aproximadamente, a concepção política de Platão (\$2). Peramás, que foi missionário no Paraguai de 1755 a 1767, ano da expulsão dos jesuítas, desenha um cuidadoso estudo comparativo entre o texto platônico e o que ele pode conhecer em primeira pessoa nas missões guaranis. Numa Europa, a seu ver corrompida pelos ideais da Revolução Francesa, a coincidência da utopia de Platão com as instituições políticas dos guaranis torna-se prova da necessidade de combater a nova filosofia política liberal e suas revoluções, em favor de um retorno a ideais de justiça ao mesmo tempo antigos e primitivos.
\end{abstract}

Palavras-chave: Platão; República; Guaranís; Peramas; utopia

Aвstract: This paper is dedicated to the study of the work De Administratione guaranica comparata ad Rempublicam Platonis commentarius written by the Catalan Jesuit José Manuel Peramás and published in 1793. The work is conceived in controversy with the liberal and illustrated modern utopias that the author qualifies as Epicurean and disrespectful of the holy institutions. With this controversial agenda Peramás regains the political utopia of Plato, expressed both in the Politeia and especially in the Laws. The most compelling argument in Peramás' quarrel against the liberal utopias of his time is that among the Guarani of the Missions, on American soil, Plato's political ideas were actually put into practice (\$2), at least approximately. Peramás, who was a missionary in Paraguay from 1755 to 1767 , the year of the expulsion of the Jesuits, produces a careful comparative study of the Platonic text and of what he could learn first-hand in Guarani Missions. The coincidence of Plato's utopia with the political institutions of the Guarani people proves the need to fight the new liberal political philosophy and its revolutions in favor of a return to the ideals of justice at the same ancient and primitive. Especially in a Europe that, in his opinion, has been corrupted by the ideals of the French Revolution.

Keywords: Plato; Politeia; Guarani; Peramas; utopia 


\section{INTRODUÇÃo}

A descoberta geral da obra que é objeto deste paper nasce literalmente de um jogo. Um dos jogos mais amados em ambas as margens do Atlântico: o jogo do futebol. Gianpaolo Romanato, no periódico vaticano L'Osservatore Romano, às véspera da Copa do Mundo de Futebol de 2010 (11/06/2010) cita a obra de José Manuel Peramás, De Administratione guaranica comparate ad Rempublicam Platonis commentarius, mais comunmente conhecida como A República de Platão $e$ os Guaranis. O texto serve de fonte para uma notícia extraordinária: o futebol nasceu entre os Guaranis das Missões da região do Paraguai e do Brasil. ${ }^{1}$

$\mathrm{O}$ interesse da obra, obviamente, supera aquele do jogo aqui descrito. De maneira especial por chamar em causa o próprio Platão e sua utopia filosófica. O livro foi publicado pelo jesuíta catalão Josep M. Peramás em Faenza, na Itália, em 1793. Nascido em Matarò, na Catalunha, em 1732, com a idade de 22 anos Peramás embarca para a América, ainda estudante jesuíta, chegando no Rio de la Plata, entre Argentina e Uruguai, em 1755. Depois de concluir seus estudos em Córdoba, em 1758, imediatamente após sua ordenação sacerdotal, é enviado como missionário para as reduções guaranis do Alto Paraná. Após um ano e meio, é chamado de volta para Córdoba para ocupar a cátedra de Retórica na Universidade. Em 1767, com a dramática expulsão do jesuítas do Novo Mundo, Peramás foge para a região da Romagna, na Itália, e mais precisamente para a cidade de Faenza, onde dedica-se à vida religiosa, ao estudo e à publicação. Em 1773, no mesmo ano de sua morte, já estava pronta para a estampa uma obra chamada $D e$ vita et moribus tredici virorum paraguaycorum. No mesmo volume, encontrava-se publicado também o livreto que nos interessa aqui mais diretamente. ${ }^{2}$

\section{O CONTEXTO SETECENTISTA}

A obra em questão, portanto, é publicada em pleno período setecentista. Um contexto histórico bastante conturbado e central para a formação da Europa.

${ }^{1}$ A notícia é pela verdade mais antiga, e se refere a um artigo, escrito entre o sério e o divertido, pelo grande etnólogo e antropólogo jesuíta, Bartolomeu Meliá, maior especialista das Missões Guaranis, na revista "Acción (junho 1999, pp. 20-22). Melià revela que Peramás não seria o 'único testemunho da invencão do futebol pelo Guaranis. Outro celebre jesuíta das missões, José Cardiel, também exilado em Faenza como Peramás, escreve em um manuscrito em 1771 (publicado na Espanha por P. Hernández em 1913 sob o título Breve relación de lãs misiones del Paraguay): "Después de la misa se reparten las faenas de toda la semana, y se van a comer y a jugar a la pelota, que ES casis u único juego. Pero no la juegancomo lo españoles: no la tiran y revuelven con la mano. Al sacar, tiran la pelota un poco en alto, y la arrojan con el empeine del pie del mismo modo que nosotros con la mano: y al volverla los contrarios lo hacentambién con el pie: lo demás esfalta. Su pelotaes de cierta goma, que salta mucho más que nuestras pelotas. Júntans e muchos a este juego y ponen SUS apuestas de una y otra parte...”.Não somente o futebol, portanto, mas também as apostas esportivas já tinham sua versão guarani.

${ }^{2}$ Veja-se para estas informações o Prólogo à tradução da obra de Peramás de 1946 por G. Furlong, que em 1925 já havia esboçado uma biografia de Peramás. 
Marcondes (2012) fala da literatura das navegações do século XVI como um lugar de desenvolvimento de uma antropologia das navegaçôes, que é resumida pelo argumento antropológico, de marca fortemente cética: haveria uma natureza humana universal? Quais os critérios para pensar o ser humano universal (que significava fundamentalmente europeu) após a descoberta do Novo Mundo? É neste período que surgem as visões idealizadas do bom selvagem, do homem naturalmente bom.

Dois séculos depois a filosofia da Ilustração do século XVIII inverte a visão paradisíaca do homem americano e do Éden na terra americana, para um discurso fortemente marcado por uma visão negativa do Novo Mundo. O discurso serve agora para legitimar a forte expansão colonial europeia, obviamente, assim como a escravidão africana. No meio desta polêmica sobre o status de humanidade a ser atribuído aos indígenas americanos a experiência das missões jesuíticas guaranis adquire uma importância decisiva. Dela se ocupam autores da grande literatura como Montesquieu, Voltaire e Raynal, entre outros (Domingues 2006, 47). O argumento antropológico é substituído pelo argumento político: é o século das grandes utopias, isto é, da exploração da possibilidade de uma sociedade justa e perfeita. Neste contexto a grande literatura europeia dedica-se, mais uma vez, a se confrontar com a América. No caso específico com uma experiência extraordinária como aquela da República jesuítica das Missões guaranis.

Um exemplo desta visão crítica setecentista é certamente o célebre Cândido de Voltaire. Publicado em 1759 o Cândido ou o otimismo é uma novela pseudônima que, ainda que não dedicada especificamente aos guaranis, representa um momento central da crítica europeia à experiência jesuítica no Novo Mundo. Inicialmente concebido como crítica sarcástica ao postulado otimista de Leibniz pelo qual este mundo seria o melhor dos mundos possíveis, o Cândido, em suas andanças pelo Novo Mundo, revela uma sociedade corrompida pela colonização espanhola (e portuguesa), pela república jesuítica e pela escravidão de origem africana. Única exceção a esta distopia é o Eldorado. Marcado pela ausência de leis, prisões e guerras, o lugar é colocado geograficamente no Peru, mas - é interessante notar aqui a finura do jogo dramático - Cândido o teria encontrado acidentalmente e já não saberia mais voltar a ele. Ainda que Voltaire critique, portanto, a realidade da ocupação americana, é ainda em terras latino-americanas que a sociedade ideal é representada (Domingues 2006, 60).

Entre os que se ocupam intensamente da experiência da Missões guaranis, encontra-se um dos maiores,opositores dos jesuítas, o Marques de Pombal. Um ano antes da expulsão dos jesuítas, em 1758, ele publica, a princípio anonimamente, o livreto Relação Abbreviada da República, que os religiosos jesuitas das provincias de Portugal, e Hespanha, estabelecerão nos dominios ultramarinos das duas monarchias. $\mathrm{O}$ argumento central do Marques de Pombal é que as reduções jesuíticas guaranis desafiavam, em seu isolamento e autossuficiência, o poder das coroas tanto portuguesa como espanhola, e uma ação militar por parte destas era 
necessária para evitar um levante dos súditos indígenas. Os padres jesuítas, por seu lado, são acusados de exercerem sobre os guaranis um poder total. Segundo Pombal, "a obediência cega implantada no seio das famílias indígenas coloca-as em um estado de escravidão pior do que a dos negros em Minas Gerais"(1957, 8). ${ }^{3}$

O livro de Peramás insere-se neste debate tomando o outro lado, isto é, como uma resposta/apologia dos jesuítas contra a desconfiança geral reservada ao homem indígena e, mais precisamente, à atuação política e eclesiástica dos jesuítas nas Missões. A resposta de Peramás, todavia, - é o caso de notar - se dá numa temporalidade póstuma, por assim dizer: o missionário jesuíta encontra-se já no exílio italiano, tendo perdido não somente a missão entre os guaranis, mas também a própria Companhia de Jesus, suprimida em 1773 pelo papa Clemente XIV. Este contexto de desterro determina tanto o tom fortemente polêmico da obra como a escolha de tecido comparativo: a República de Platão.

As primeiras linhas do texto não deixam dúvidas com relação a qual é a intenção do autor, que chama a contenda a insanientis Philosophiae Epicureus grex:

Se alguma vez foi oportuno por em prática aquela forma de governo que propõe Platão em seu célebre livro $A$ República, é certamente nestes tempos em que um rebanho epicurista de filósofos dementes, em seu ódio contra as santas instituições de nossos antepassados e de toda forma reta de governo, subverte todo o existente e excogita algo novo todo dia para conseguir a plena felicidade dos povos. Porque então não adotam aquela forma do grande filósofos de quem Cicero denomina o mais sábio da Grécia? Sei bem que há nela erros inadmissíveis; reconheço e confesso isso. Mas também contem coisas belíssimas e excelentes. Reconheçam elas e as coloquem em prática (1).

Um forte tom retórico do autor é uma marca do texto. A hipótese a ser demonstrada, que houve de fato alguma vez um lugar onde os ideais políticos de Platão se realizaram, é assim metodologicamente delineada:

Em nossa exposição seguiremos o seguinte método: daremos uma síntese do pensamento de Platão sobre cada um dos temas, em seguida referiremos o que se praticava entre os guaranis; ao final o leitor julgará por si mesmo se entre as normas daquele e as práticas destes haja semelhança ou discrepância (4).

A obra está organizada em 27 capítulos e 344 parágrafos numerados sucessivamente. Uma Apóstrofe aos Filósofos Liberais está posta ao final do livro, junto com um resumo de seus argumentos. Estilo e organização do texto fazem lembrar diretamente aqueles dos exercícios retóricos escolásticos. Para contrastar

\footnotetext{
${ }^{3}$ Peramás responderá dizendo que os jesuítas protegiam os índios da violência das coroas, tratando-os como "filhos, não escravos"(XXII, 246).
} 
a forte implicação da memória e da autopsia do próprio Peramás - e como mais um artifício retórico escolástico - o autor declara:

Para que ninguém pense que aqui inventamos alguma coisa com a intenção de forçar os termos de comparação, declaramos que quanto teremos a dizer, apesar de ter vivido por muito tempo entre os guaranis, o derivaremos de documentos já publicados, a saber: dos escritos de... (5).

De fato a obra, para além de contar com uma enorme quantidade de citações de autores clássicos (de Cicero a Tomás de Aquino, passando pela lírica e a biografia), refere-se a uma ainda maior quantidade de obras dedicadas às missões jesuíticas: o historiador italiano Muratori e diversos jesuítas são arrolados como testemunhas da veridicidade da narração. Filósofos e polemistas setecentistas como Pauw e Raynal são frequentemente criticados. Esta estratégia de utilização direta de fontes primárias para comprovar a narração, para além de técnica de persuasão, é também a marca do estilo literário setecentista. Exemplo disso é a própria Relação - acima citada - do Marquês de Pombal, que além de citar um diário anônimo escrito por alguém que esteve nas missões, inclui em apêndice quatro documentos, "escritos na língua dos índios e fielmente traduzidos para o português", a dizer do Marquês) que comprovariam as intenções subversivas de jesuítas e indígenas (Domingues 2006, 50).

Como anunciado, portanto, os diversos capítulos desempenham uma comparação sinóptica entre o que Peramás resume (citando frequentemente as páginas da República e das Leis) do pensamento político platônico e o que teria sido a República guarani. Um breve olhar para o sumário dos capítulos dá a ideia da amplitude e da precisão desta comparação:

\section{INTRODUÇÃO}

Cap. I.

Cap. II.

Cap. III.

Cap. IV.

Cap. V.

Cap. VI.

Cap. VII.

Cap. VIII.

Cap. IX.

Cap. X.

Cap. XI.

Cap. XII.

Cap. XIII.

Cap. XIV.
Em que lugar deve edificar-se uma cidade

A forma que deve ter a cidade

Simplicidades nas casas e no enxoval

Unidade da etnia dos integrantes de uma cidade

Número de cidadãos e de casas

O templo e os sacrifícios

A inquisição contra os ímpios

A comunhão dos bens

As bodas

A educação

A música

A dança

O trabalho do dia

As refeições públicas 

Cap. XV.
As artes
Cap. XVI.
O progresso das artes
Cap. XVII.
Origem dos povos
Cap. XVIII.
O comércio
Cap. XIX.
Os peregrinos
Cap. XX.
As roupas
Cap. XXI.
Os magistrados
Cap. XXII.
As leis
Cap. XXIII.
A reta disciplina
Cap. XXIV.
Opinião do filósofo Reynal sobre a organização dos
Cap. XXV. Outras opiniões sobre o regime guarani
Cap. XXVI. Os castigos
Cap. XXVII. Funerais e cemitérios
EPÍLOGO da comparação
APÓSTROFE aos filósofos liberais
CONCLUSÃO guaranis

\section{Comunhão dos Bens}

A comunhão dos bens é certamente um dos temas centrais das utopias setecentistas e motivo fundamental de interesse e debate, entre os intelectuais do tempo, sobreo comunismo das missões jesuíticas. A maneira como Peramás trata a questão revela os contornos de seu projeto utópico e as formas de seu diálogo tanto com Platão como com as utopias liberais contemporâneas. O cap. VIII, intitulado exatamente $A$ Comunhão dos bens, é inteiramente dedicado a um exame cuidadoso desta questão. Assim inicia-se o capítulo:

Depois de sua atenção para com a Religião nada foi tão caro a Platão quanto a comunhão dos bens, sem a qual - ele pensava - de nenhuma forma a cidade podia subsistir. Assim deu entender em certa ocasião na qual, convidado pelos habitantes da Arcádia a organizar a cidade deles, negou-se por saber que eles não admitiam a igualdade de riquezas. No tratado (sic) $A$ República não exige nada com mais intransigência do que a vida comum: o mesmo faz nos doze livros d'As Leis, escritos para a colônia de Magnésia que os cretenses deviam fundar (VIII, 42).

Peramás, ao mesmo tempo em que faz uma comparação interna ao corpus platônico, demonstrando perceber uma diferença de intensidade utópica - por assim dizer - entre República e Leis, afirma:

Em estas [Leis] é sem dúvida mais moderado e cauto com relação à comunhão dos bens. Pois nos livros de República ele foi demasiado longe em seu afã de tornar todas as coisas comuns, e cometeu graves erros, como veremos mais adiante (VIII, 42). 
O escândalo de Peramás acentua-se com relação a uma modalidade específica desta comunhão dos bens platônica:

O engenho portentoso de Platão, enganado por aquele célebre provérbio grego pelo qual "tudo é comum entre os amigos", koináphilon, falhou por completo nos livros d'A República ao pretender que mulheres e filhos fossem comuns; e isso não por ele ser mulherengo - pois viveu celibatário e casto a vida toda (IX, 53).

O erro de Platão é, todavia, escusável, fundamentalmente, por ele ser somente um ser humano: "temos de reconhecer que aqui Platão errou completamente, e apesar de ser chamado 'o divino', afinal era um homem” (IX, 53 n1). Mas não merecem a mesma compreensão os utopistas contemporâneos, que são chamados na mesma passagem de "rebanho aloprado dos modernos sofistas, cuja cegueira supera a de Platão" (XI, 55).

A Platão e aos filósofos modernos o autor opõe a experiência das Missões: "entre os guaranis algumas coisas eram comuns, outras não" (VIII, 45). Havias entre eles uma estrutura de divisão da terra que previa a existência de dois tipos de campos: o abambaé, que era "propriedade particular de cada índio" e o tupambaé que era o campo comum, cultivado por toda a redução e cujos frutos (fundamentalmente trigo, legumes, algodão) eram armazenados nos depósitos como "fundo comum" de assistência social, que permitia cuidar dos "doentes, meninos, meninas e viúvas" (VIII, 47).

A centralidade do tema é evidente também pelo fato que, neste caso da divisão das terras em privadas e comuns, Peramás chama em causa nominalmente o mais importante utopista de seu tempo: o próprio Thomas Moore.

Isso o teria aprovado, sem dúvida, o famoso Thomas Moore, que desejava que todos os integrantes de sua república UTOPIA fossem agricultores (VIII, 48).

$\mathrm{Na}$ questão da comunhão de bens, portanto, a prática das missões guaranis supera tanto certo exagero platônico como os "gritos insensatos que hoje ecoam por toda parte de igualdade, comunhão de bens e equidade das riquezas"(VIII, 42, n1). Esta posição crítica de Peramás precisa ainda superar um obstáculo importante: a tradição pela qual a comunhão de bens era praticada na comunidade cristã primitiva. Peramás admite isso. Mais precisamente, a utopia comunista da Igreja primitiva é diretamente relacionada à filosofia platônica:

Suponhamos que Pedro [o apóstolo] quando pobre, mal vestido e descalço entrou em Roma, tivesse começado a tratar de persuadir publicamente os patrícios, senadores, ediles, tribunos militares e até o próprio Imperador para que, abolidos os títulos honoríficos e fazendo uma montanha com as riquezas e os bens familiares, as repartissem todas com os plebeus e vivessem todos em perfeita igualdade. O que teria acontecido? O Senado e o Povo Romano teriam pensado que chegara da Grécia um discípulo de Platão e o teriam 
embarcado para Creta, depois de injuria-lo com palavras, visto que Platão havia imaginado sua república para os Cretenses e não para os Quirites (317).

A imagem de Pedro Apóstolo ser confundido com um discípulo de Platão por causa de seu comunismo é realmente excepcional e cria para Peramás um duplo problema, pois Platão e o Evangelho são de fato os dois horizontes principais de referência e idealidade. Peramás resolve inicialmente o problema afirmando o seguinte:

não foi esta [da comunhão dos bens] uma lei geral para todos, e sim um toque sublime da glória daquela santíssima comunidade, um método de vida admirável e um estado de seres perfeitos (...). Mas com respeito a cidadãos que não tem miras tão elevadas, é conveniente que disponham de seus bens e de seus campos (...). (331).

Um pouco ao estilo platônico, portanto, a comunhão dos bens - ainda que ideal - não seria simplesmente aplicável a todos. No entanto, esta correspondência entre a utopia comunista platônica, a prática da comunidade cristã primitiva e os ideais dos ilustrados requer um suplemento de reflexão e argumentação por parte de Peramás. Ao argumentar contra Platão e o Evangelho, Peramás revela-se de fato como um pensador setecentista, apesar de tudo. Assumindo uma visão francamente liberal, acaba - em primeiro lugar - por considerar a igualdade um problema para o progresso, devido à falta de competição:

todas as famílias eram quase iguais e possuíam os mesmos bens, a não ser que alguém cultivasse seu campo com maior diligência (...). Isso introduzia uma desigualdade insignificante e, além , constituía um estímulo (VIII, 49).

Em segundo lugar, em favor deste sistema de terras públicas e privadas, é chamada em questão uma analogia natural: os guaranis são comparados com as abelhas, que possuem cada uma seu mel, mas somente depois de colaborarem para a construção da colmeia coletiva. ${ }^{4} \mathrm{O}$ mesmo argumento do natural versus civilizado é apresentado com relação às formas de relações econômicas deste sistema, notadamente à moeda:

Não se utilizava moeda entre os guaranis; seguindo o uso primitivo, faziam escambo de mercancia com mercancia, sistema este mais apropriado à simplicidade natural (XVIII, 175).

${ }^{4}$ As abelhas são indicadas pelo próprio Aristóteles como exemplos de organização política ideal na primeira página de sua Política. 
Um argumento natural é assim argumento para contrapor-se ao comunismo platônico e cristão original. Assim, ao novamente reclamar de Platão, Peramás afirma:

Quantas e quão graves dificuldades cria esta comunhão de bens platônica e igualdade de todos! Em nenhuma parte até agora existiu uma cidade que se regesse por estas instituições, nem creio que jamais poderá existir no futuro (322).

Desta forma (“jamais poderá existir no futuro") a questão da comunhão dos bens introduz o grande pano de fundo da obra de Peramás, isto é a polêmica com as utopias de seu tempo.

\section{UTOPIAS TRANSATLÂNTICAS}

No Apóstrofe final aos Filósofos Liberais Peramás assim resume a questão:

Terminada a comparação do regime guarani com a República de Platão, se algum entre os filósofos atuais (que, seguindo a norma dos antigos atenienses, não se ocupam com outra coisa senão dizer ou ouvir novidades) me perguntasse se julgo possível existir na Europa algo semelhante àquela forma de governo, responderia: foi possível num outro tempo, não em nossos dias. Foi quando os europeus, antes de cultivarem as artes e fundar suas cidades, viviam em grupos e andavam errantes, pouco ou nada diferentes das tribos da América (307).

A indicação de que tanto a república de Platão como aquela dos Guaranis - que as linhas gerais do estudos sinóptico mostram não diferirem significativamente -foram possíveis em outros tempos, mas não em nossos dias, resume bem a polêmica de Peramás com as utopias ilustradas de seu tempo. O motivo alegado pela impossibilidade da Europa viver a utopia guarani é seu estágio civilizatório, por assim dizer, isto é seu afastamento da condição natural. Em diversa ocasiões Peramás revela seu olhar naturalizador ao tratar dos índios. Estes, como as feras encantadas pela música de Orfeu,

Se à maneira de Orfeu forem amansados pouco a pouco, se forem instruídos para os trabalhos úteis com suavidade e delicadeza (pois a doçura da bondade - diz Valério Máximo - penetra as inteligência dos bárbaros) (...) se renderão espontaneamente (309).

A identificação dos índios com os bárbaros permite a Peramás lançar mão de sua grande erudição clássica para uma obra de comparação que supera imediatamente a república de Platão. É o caso de Tácito, por exemplo: 
Cornélio Tácito, ao falar da antiga Germânia, parece descrever os costumes dos índios da América melhor do que aqueles dos germanos (313).

Platão também se utiliza desta estratégia de validação do projeto utópico afirmando ser ele kataphysin, isto é conforme a natureza ( $R$. V 455d). A conformidade com a natureza é chamada em causa com uma direta função de crítica às instituições de seu tempo ( $R$. V 456c). Insere-se neste mesmo ponto de contato entre Platão e Peramás o fato que, nas Leis de Platão o desenho da cidade ideal é um exercício teórico-prático permitido por uma ocasião especial: a fundação de uma colônia, uma cidade ex novo, portanto. Como a experiência da república guarani. A possibilidade, por assim dizer, de zerar tudo e poder fundar uma cidade de um nada que é ao mesmo tempo um vazio político e uma tabula rasa antropológica - tentação fortemente brasiliense - está à base de ambos os projetos. Como nas primeiras experiências antigas de discurso utópico, quando a referência era à Idade de Ouro, a utopia significa aqui um retorno a um passado ideal. Com a diferença de que o passado não é tecnicamente ideal, pois aconteceu, a utopia foi realizada nas reduções guaranis de Paraguai e Brasil.

Ainda assim, a utopia das missões é dita, como vimos, impraticável tanto no presente como no futuro. Praticada sim, no passado, onde, todavia, permanece, não tendo mais lugar - é esta precisamente a etimologia da utopia - na Europa do século XVIII. Também Platão insiste na praticabilidade, na possibilidade do paradigma político construído no céu e em palavras (Vegetti 2010, 264). Mas a diferença de Peramás sua tensão utópica é toda voltada para o futuro. Meliá fala, no caso das reduções guaranis como apresentadas por Peramás, de uma utopia concretizada, o que daria ao texto um certo ar saudosista e conservador (Domingues 2010). Não creio pessoalmente que possa existir algo como uma utopia concretizada. É verdade que a utopia de Peramás é voltada inteiramente ao passado, e não revela qualquer impulso para a construção da mesma no futuro. Pelo contrário, há uma distopia fortemente desenhada pela indicação clara de que é impossível qualquer proposta deste tipo nos dias atuais. Mas, ao mesmo tempo, a experiência do autor é continuamente confrontada com a idealidade política: a filosofia política de Platão, a história e a doutrina cristãs e, ainda que em polémica, os ideais revolucionários setecentistas. Esta comparação dá ao texto as feições de uma investigação teórica e não somente etnográfica, portanto sobre as melhores formas de vida comum e de organização do estado. Reflexão que não propõe uma república ideal no futuro simplesmente porque ela - segundo Peramás - havia ficado para trás, num passado que, ainda que recente, é de fato já inalcançável.

Peramás considera o regime político das missões guaraníticas, em comparação com a república de Platão, como o melhor possível. Neste sentido a proposta de Peramás é realmente utópica, por representar uma allegedly perfect society, na definição de utopia por Segal $(2012,5)$. E acaba por constituir-se numa teoria 
política normativa, à moda de Rawls: ainda que irrealizável em sua totalidade, a descrição das missões é um modelo de vida política a ser considerado pela Europa do final de século XVIII.

\section{Conclusão}

A experiência dos guaranis torna-se assim motivo para um diálogo relativamente amplo com a Ilustração europeia a respeito dos ideais políticos que deveriam reger a Europa. Peramás traz para o debatea utopia que ele próprio teria testemunhado, aquela das reduções guaranis, fundadas sobre ideais clássicos e cristãos. Os modelos utópicos ilustrados aos quais Peramás quer contrapor esta utopia realizada buscam ao contrário uma quebra presentista com o passado. A bem ver, todavia, Peramás e sua utopia se revelamainda filhos de sua época e mais ilustrados do que o próprio autor poderia admitir: ainda que historicamente concretizada, a utopia guarani só se realiza fora da história, por assim dizer, isto é fora da continuidade com as utopias clássicas e cristãs que marcam a historia do pensamento ocidental. A experiência da missões guaranis nas regiões do Alto Paraná é algo imprevisto e imprevisível, isto é não é o resultado da idealidade política clássica e cristã, que acabaram por produzir ao contrário a crise da Europa do século XVIII. A referência a Platão é certamente uma referencia post factum, não uma direta influência sobre a constituição da vida política guarani. ${ }^{5}$ Entre os trópicos utópicos e a distopia da Europa setecentista, o exilado e desterrado jesuíta catalão parece estar escondido por trás da mureta, como o filósofo que vive como estranho em sua própria cidade descrito na República de Platão, e está à espera de tempos melhores para sua atuação política ( $R$. 325e). Peramás busca em Platão (e nos clássicos mais em geral) um horizonte de referência que lhe permita interpretar a derrota histórica e ideológica de um projeto político alternativo.

${ }^{5}$ Sobre a real influencia das utopias, antigas e contemporâneas, para a construção da republica guarani, Meliá é bastante cético a esse respeito: "Los jesuitas han conocido tal vez algunas de las filosofías políticas inspiradas en los clásicos del pensamiento grecolatino, puestas de moda en la Europa del Renacimiento. Se ha querido escuchar ecos de la Utopía de Tomás Moro, o la Ciudad del Sol, de Campanella, en algunas instrucciones y orientaciones jesuíticas. No hay, sin embargo, ningún apoyo textual para tales suposiciones [...] Las Misiones o Reducciones jesuíticas de Guaraníes son una historia pragmática, hecha día a día, en la cual confluyen más decisiones prácticas que ideas teóricas. La base está ante todo en principios evangélicos y en reglas de sentido común, cercanas a lo que hoy da en llamarse inculturación. Muchas de las soluciones encontradas hay que atribuirlas probablemente más a los mismos Guaraníes que a los jesuitas" (Meliá, 2004, 11-12). 


\section{REFERÊNCIAS BibLIOGRÁFICAS}

Cornelli, G. (2009), "A paixão política de Platão: sobre cercas filosóficas e sua permeabilidade", Archai 2: 15-29.

Domingues, B. H. (2006), "As missões jesuíticas entre os guaranis no contexto da Ilustração”, História 25: 44-69.

Domingues, B. H. (2007), "Platão e os Guaranis: uma análise da obra de Joseph Perramás à luz das utopias européias renascentistas e das teorias ilustradas sobre o Novo Mundo", in XXIV Simpósio Nacional de História, 2007, São Leopoldo, pp.???.

Domingues, B. H. (2008), "Platão e os Guaranis: uma análise da obra de José Perramás à luz das utopias européias renascentistas e das teorias ilustradas sobre o Novo Mundo", História Unisinos I: 13-3.

Domingues, B. H. (2010), "Platão e os Guarani: uma leitura da obra de José Peramás", IHU On-Line (UNISINOS)328: 23-30 [Entrevista].

Marcondes, D. (2012), "Montaigne, a descoberta do novo mundo e o ceticismo moderno", Kriterion 53, no 126: 421-433.

Melía (2004) = Peramás, J. M. (2004), Platón y losguaranies. Traducción de F. Fernández Pertiñez y Bartomeu Melià. Asunción.

Muratori, L. A. (1997), El cristianismo feliz en las misiones de los padres de la Compañia de Jesús en Paraguay. Traducción, introducción y notas de Francisco Borghesi. Santiago de Chile.

Peramás, J. M. (2004), Platón y losguaranies. Traducción de F. Fernández Pertiñez y Bartomeu Melià. Asunción.

Peramás, J. M. (2004), Diario Del destierro. Córdoba.

Peramás, J. M. (1946), Platón y los guaranies. Traducción de Juan Cortésdel Pino, prólogo de Guillermo Furlong. Buenos Aires.

Peramás, J. M. (2009), De Vita et Moribus Sex Sacerdotum Paraguaycorum (1791). Kessinger.

Peramás, J. M. (1994), Guaranica = De administratione guaranica comparata ad rempublicam Platonis commentarius. Hamilton.

Pombal, S. J. de C. e M., Marquês de (1757), Relação abbreviada da republica, que os religiosos jesuitas das provincias de Portugal, e Hespanha, estabelecerão nos dominios, ultramarinos das duas monarchias, e da guerra, que nelles tem movido, e sustentado contra os exercitoshespanhoes, e portuguezes. Lisboa.

Segal, H. P. (2012), Utopias: a Brief History from Ancient Writings to Virtual Communities. Oxford.

Vegetti, M. (2010), Um paradigma no céu: Platão político, de Aristóteles ao séc. XX. São Paulo. 